\title{
EDITORIAL
}

\section{High oil prices - Haven't we seen this all before!}

Journal of Revenue and Pricing Management (2008) 7, 239-241. doi:10.1057/rpm.2008.32

With oil prices approaching $\$ 140$ a barrel (June 2008 ) and moving towards $\$ 200$ by the end of the year, demand for air travel is faltering as consumer spending is squeezed and stagflation sets in, all reminding us of the last oil shock in 1974 , when oil prices rose from $\$ 2$ to $\$ 8$ overnight. Oil prices at $\$ 140$, combined with falling house prices, tension in the Middle East, food inflation and increased demand for consumerism in China, have put the world on a course of meltdown (some would say) or prolonged economic downturn. But we have seen this all before: remember 1974 and 1979 (maybe you don't)?

\section{THIS IS WHAT HAPPENED IN 1974!}

The impact of rising prices in 1974 on international travel according to the UN World Tourism Organization (2005) was:

1st year (1975): Continued growth in international tourism

In the first year following the oil shock of 1974, the impact on tourism was not generally perceptible. International tourism demand continued to grow rapidly, at a rate of 8.1 per cent, from 1974 to 1975 . This growth was even stronger than that recorded in previous years (3.4 per cent in 1974 and 5.2 per cent in 1973).

2nd year (1976): Slowdown in tourist flows

By the second year, adjustment policies introduced in late 1975 had led to a decline in purchasing power in many oil-importing countries, which in 1976 triggered a steep slowdown in tourism demand, with a growth of only 2.3 per cent worldwide, 1.5 per cent in Europe and -4.9 per cent in Africa.

3rd year (1977): Strong recovery in tourism activity During the third year, 1977, tourism growth resumed its earlier pace and even regained some lost ground, with a rate of 8.2 per cent (Figure 1, Table 1).

As a result, world economic growth (GDP) in 1975 fell to 1.9 per cent and then subsequently rose to 5.1 per cent in 1976 and 4.4 per cent in 1977. Therefore, the impact of the oil shock in 1974 was only limited to one year, with recovery across all markets in subsequent years.

\section{WHAT HAPPENED IN 1979...}

The oil shock of 1979 was a result of the Iranian revolution. This crisis came at a time when the world was still recovering from the first crisis in 1974; hence the second impact was more marked. The effect of the crisis was a slowdown in economic growth and disposable income across most western economies.

1st year (1980): Continued growth in tourism activity

During the first year following the oil shock of 1979, international tourism demand continued to increase at a sustained pace, with 2 per cent growth in world tourism in 1980. 


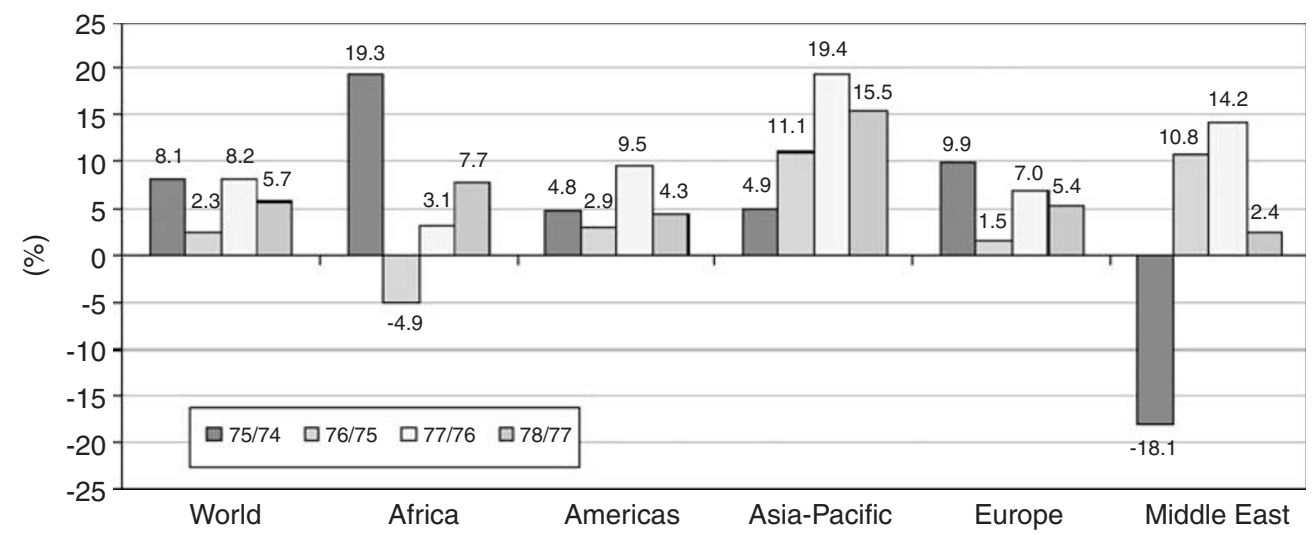

Figure 1: Trends in world tourism: International arrivals (\% change over previous year) Source: World Tourism Organization (UNWTO)

Table 1: Trends in world tourism 1974-1977: International arrivals (millions)

\begin{tabular}{lrrrr}
\hline Regions & 1974 & 1975 & 1976 & 1977 \\
\hline World & 205.7 & 222.3 & 227.4 & 246.1 \\
Africa & 3.9 & 4.7 & 4.4 & 4.6 \\
Americas & 47.7 & 50.0 & 51.5 & 56.4 \\
Asia-Pacific & 9.7 & 10.2 & 11.3 & 13.6 \\
Europe & 140.0 & 153.9 & 156.2 & 167.2 \\
Middle East & 4.3 & 3.5 & 3.9 & 4.5 \\
& & & & \\
\hline
\end{tabular}

Source: World Tourism Organization (UNWTO)

2nd, 3rd, 4th years $(1981,1982,1983)$ : Stagnation in tourism flows

By the second year, 1981, tourism demand had stagnated, with a barely positive growth of 0.2 per cent. As distinguished from the first oil shock, this stagnation was to last three years and even to become slightly recessionary in 1982, with a negative growth of -0.5 per cent, followed by a rate of only 1.8 per cent in 1983 . This stagnation or recession had its primary impact in the world's two largest tourismreceiving regions: Europe and the Americas. The Americas, and the United States in particular, also suffered the repercussions of a sharply rising dollar during this period, contributing to a decline of unrivalled proportions
(-4.5 per cent) in tourist arrivals to the Americas in 1982.

5th year (1984): Strong recovery in international tourism

It was not until the fifth year following the second oil shock of 1979 that earlier rates of growth in international tourism demand recovered. As during the first oil shock, growth rates in world tourism even caught up with their earlier pace, with a positive growth of 8.8 per cent in 1984, and a continuing sustained growth of 4.3 per cent in 1985 and 3.2 per cent in 1986 (Figure 2).

As a consequence, the second oil shock of 1979 resulted in Europe entering a prolonged period of stagflation, with international arrivals falling by 2.2 per cent in 1980. Europe did not recover until 1984. In the Americas, the high exchange rate for the US dollar had lasting effects, prolonging recession for international demand to the region at a time when growth was returning to the rest of the world. In 1985, when the US dollar peaked, tourist arrivals to the Americas declined by 3.4 per cent (Table 2).

The impact of the second oil shock on international tourism was therefore greater than the first, because between 1980 and 1983, growth in international arrivals was limited with an increase of only 1.4 per cent. 


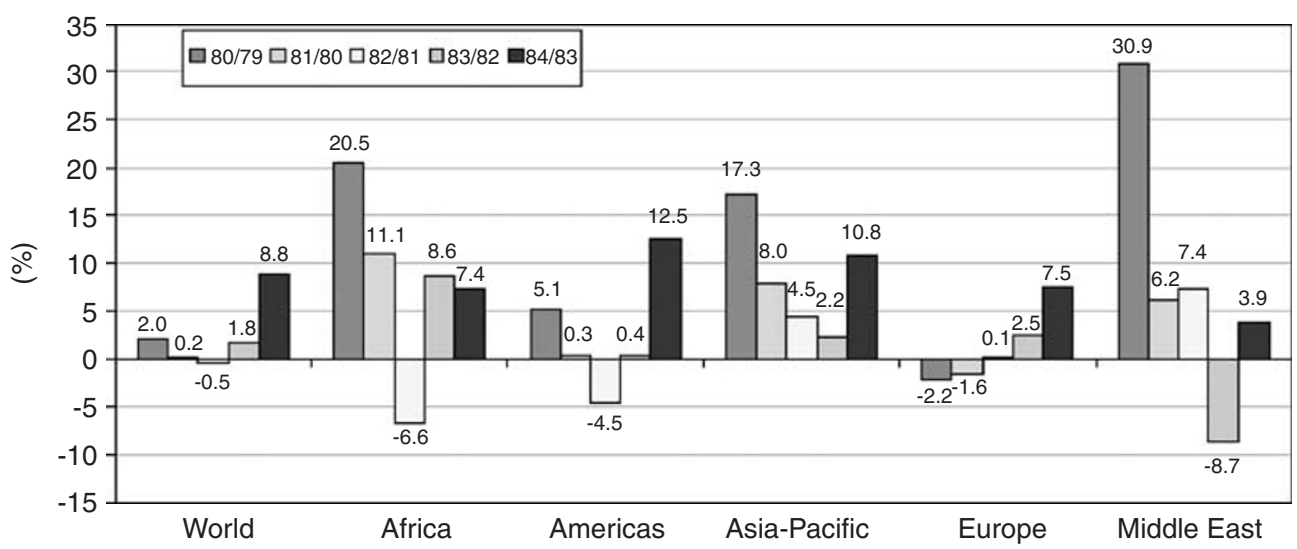

Figure 2: Trends in world tourism: International arrivals (\% change over previous year) Source: World Tourism Organization (UNWTO)

Table 2: Trends in world tourism 1979-1983: International arrivals (millions)

\begin{tabular}{lrrrrr}
\hline Regions & 1979 & 1980 & 1981 & 1982 & 1983 \\
\hline World & 272.1 & 277.6 & 278.1 & 276.5 & 281.6 \\
Africa & 6.0 & 7.3 & 8.1 & 7.5 & 8.2 \\
Americas & 59.3 & 62.3 & 62.5 & 59.7 & 59.9 \\
Asia-Pacific & 19.6 & 23.0 & 24.9 & 26.0 & 26.6 \\
Europe & 181.4 & 177.5 & 174.6 & 174.8 & 179.1 \\
Middle East & 5.7 & 7.5 & 8.0 & 8.5 & 7.8 \\
& & & & & \\
\hline
\end{tabular}

Source: World Tourism Organization (UNWTO)

\section{IT MIGHT NOT SEEM LIKE IT, BUT WE ARE IN A BETTER POSITION THAN IN 1974 AND 1979}

But it is not all doom and gloom. There are good reasons to believe that the economic consequences of a jump in oil prices will be less severe now than they were in the 1970s and early 1980s (Yeoman et al., 2007). Energy conservation is stronger than in the 1970s, due to government taxation policies. Additionally, a shift to other fuels and a decline in heavy industries has made rich economies much less dependent on oil than they used to be. Since the early 1970s, the amount of oil consumed per real dollar has fallen by almost half in rich countries. In addition, high oil prices encourage innovation and conservation. This means the development of better aircraft that are more fuel efficient and the use of alternative energy sources. The problem is that the tourism and transport industries have not invested enough in new technologies to foresee the present oil shock. Oil is running out, but the world did not come to an end when we moved from a wood to a coal economy or from a coal to an oil economy. Today, we are in a transformation process from coal to hydrogen. It is going to hurt, but it isn't the end of the world.

\section{References}

UN World Tourism Organization. (2005) The Impact of Oil Prices on International Tourism. Accessed at www.un-wto.org on the 4th June, 2008.

Yeoman, I., Lennon, J., Greenwood, C., Blake, A., Galt, M. and McMahon-Beattie, U. (2007) 'Oil depletion: what does this mean for Scottish tourism?', Tourism Management, 28, 1354-1365.

Ian Yeoman Editor 